Doctrina

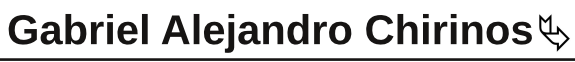

\section{Regulación y tributación en el mercado de criptoactivos, una perspectiva de derecho comparado}

\section{Criptoassets Market Regulation and Taxation, a Perspective of Comparative Law \\ Tributação no mercado criptoativo, uma perspectiva do direito comparado}

Resumen: El presente artículo de investigación pretende exponer el masivo problema que presentan las Administraciones Tributarias en cuanto a la fiscalización y cobro a las transacciones realizadas con Criptoactivos, todo esto debido a la digitalización y apertura de los mercados actuales y la masividad de las operaciones que se realizan actualmente, además de abordar una definición que permita la garantía de los derechos del contribuyente explicando las formas que tiene la Administración de intervenir en la economía, así como también, proveer a las Administraciones Tributarias el cómo abordar nuevas perspectivas que se adapten a la digitalización de los mercados e identificar cada uno de los elementos que constituyen la obligación tributaria en la sobrevenida intervención estatal en el mercado de Criptoactivos.

Palabras Clave: derecho administrativo, derecho tributario, tributación, criptoactivos, blockchain, regulación

Abstract: This research article intends to expose the massive problem presented by the Tax Administrations regarding the control and collection of transactions made with Crypto assets, all this due to the digitalization and opening of current markets and the mass of the operations carried out Currently, in addition to addressing a definition that allows the guarantee of the rights of the taxpayer explaining the ways in which the Administration of

Abogado. Egresado de la Universidad Católica Andrés Bello (2013), Caracas, Venezuela, con estudios en las Especializaciones de Derecho Administrativo (2015) y Derecho Financiero y Tributario (2018) en la Universidad Católica Andrés Bello. ORCID: 0000-0002-2092-4118

$\triangle$ gabochirinos@gmail.com 
Intervening in the economy has, as well as providing the Tax Administrations how to address new perspectives that adapt to the digitalization of the markets and identify each of the elements that constitute the tax obligation in the state intervention in the Cryptos sets market.

Keywords: Administrative Law, Tax Law, Taxation, Crypto assets, Blockchain, Regulation

Resumo: Este artigo de pesquisa pretende expor o enorme problema apresentado pelas administrações tributárias em relação ao controle e cobrança de transações realizadas com criptoativos, tudo isso devido à digitalização e abertura dos mercados atuais e à massa das operações realizadas Atualmente, além de abordar uma definição que permite a garantia dos direitos do contribuinte, explicando as maneiras pelas quais a Administração de Intervenções na economia tem, além de fornecer às Administrações Fiscais como abordar novas perspectivas que se adaptam à digitalização de mercados e identifique cada um dos elementos que constituem a obrigação tributária na intervenção estatal no mercado criptoativo.

Palavras-chave: direito administrativo, direito tributário, tributação, criptoativo, blockchain, regulamentação

Recibido: 20190930

Aceptado: 20191220 


\section{Introducción}

En el último año se ha registrado un crecimiento exponencial en las transacciones con Criptoactivos ${ }^{(1)}$, como medio de pago o inversión, generando importantes ganancias para aquellos que se atreven a usarlos. Junto con este crecimiento se ha hecho presente, permanentemente, el debate y la preocupación de las entidades gubernamentales y financieras a nivel mundial por establecer iniciativas que normen este mercado y sus transacciones, sin embargo, en muchos países aún no se establecen normativas que regulen las operaciones con Criptoactivos.

La crisis financiera de 2008, ocurrida por el otorgamiento indiscriminado de créditos inmobiliarios y la falta de regulación del mercado de derivados financieros en EE.UU., que propició apalancamientos imprudentes y el eventual colapso del sistema financiero, fue un momento crucial para el desarrollo y aplicación de uno de los Criptoactivos más populares en la actualidad, el Bitcoin (BTC), una persona actuando bajo el seudónimo de Satoshi Nakamoto, liberó un nuevo protocolo para pago electrónico Peer to Peer o P2P, que usaba el Bitcoin como medio organizado para transferencias de valor entre los usuarios. Este nuevo medio electrónico establece un set de reglas en la red, que garantizan el resguardo de la información entre los usuarios, sin la necesidad de ser controlada, administrada o aprobada por Terceros. Sin embargo, no es hasta el 2009, que entra en funcionamiento públicamente la red Peer to Peer. Es en esencia un código de fuente abierta, libre, para que todos puedan participar en una nueva forma descentralizada de la economía. Como explica Don Tapscott "más que un internet de la información es un internet del valor o del dinero” (Tapscott y Tapscot, 2018, 23).

Aceptado en su uso, el Bitcoin fue seguido por la creación y empleo de una serie de instrumentos digitales descentralizados, todos caracterizados por la validación de sus transacciones a través del esquema Peer to Peer (usuario-a-usuario) y el uso de la criptografía. A estos instrumentos, vista su funcionalidad debido al intercambio por bienes y servicios, se le ha denominado, casi de manera indistinta, criptoactivos, criptomonedas, criptodivisas, moneda digital y moneda virtual, a pesar de que puedan no compartir las mismas características del dinero fiduciario. 
El crecimiento de los Criptoactivos, tanto en valor como en número, así como en funcionalidad, ha sido exponencialmente, tomemos el ejemplo de las variaciones del Bitcoin desde su fecha de lanzamiento: en enero de 2009, se encontraba en valor 0 US\$, y no es sino hasta el 2010 que adquiere un valor en dinero fiduciario, el mismo se correspondía a 0,49 centavos de dólar, alcanzando su máximo en diciembre de 2017, con 18.737 US\$, llegando a venderse hasta 20.000 US\$. Las fluctuaciones en el precio responden a los diferentes comportamientos de los usuarios, por ejemplo, si se mantiene como reserva de valor, el Bitcoin aumentará su precio, permitiendo su apreciación. En noviembre de 2017, el valor total de mercado de todos los bitcoins en circulación rondaba los 110.000 millones de dólares, otorgándole un valor mucho mayor que el de la oferta monetaria amplia de las monedas nacionales. La apreciación resultante en el valor de mercado de los bitcoins es esencial para el buen funcionamiento de Bitcoin, ya que es el motivo de que los mineros tengan un aliciente para invertir en electricidad y capacidad de procesamiento en la verificación honesta de las transacciones. Si Bitcoin hubiera sido creada con una política de dinero tradicional, como recomendaría un economista keynesiano o uno monetarista, su masa monetaria hubiera crecido en proporción al número de los usuarios o las transacciones, devaluándose a medida que se incorporen más personas en el sistema.

El aumento de las transacciones en los diferentes Criptoactivos, han llamado la atención de diferentes gobiernos. Estados Unidos, por ejemplo, toma interés no por el valor generado por las transacciones, sino por el temor de que fuesen usados para la legitimación de capitales y financiamiento del terrorismo, esto porque entendían que las operaciones realizadas en Bitcoin eran bajo una forma de anonimato absoluto, permitiendo la elusión o evasión de las transacciones realizadas con Criptoactivos.

Luego, el foco cambia, dado que los Criptoactivos “adquieren” ciertas características del dinero, estas operaciones no se realizaban bajo el esquema del mercado financiero tradicional, por el contrario, eran operaciones inmediatas entre usuarios, sin necesidad de la intermediación financiera tradicional, y sus respectivas Haciendas no recibían contribución alguna por este tipo de operaciones.

Retomemos el objeto de nuestro estudio: dado que, los usuarios y el número de transacciones crecen a diario, además de su relevancia como medio para conservación y transferencia de valor, se constituyen en operaciones económicas o hechos económicos relevantes, los cuales son de gran importancia para los Estados, sin embargo, no existe una solución homogénea, ni acuerdos conceptuales únicos que permitan una tributación armónica basada en conceptos y herramientas informáti- 
cas idóneas. Así, los Colegios de Contadores han tratado de subsumir los criptoactivos dentro de las Normas Internacionales de Información Financiera (NIIF) llegando a convertirse en criterios armonizadores a efectos contables dentro de las empresas que están interesadas en incluirlos en parte de la vida económica.

Uno de los principales problemas identificados es la falta de conceptualización de los Criptoactivos, la forma en cómo los distintos Gobiernos intervienen en la esfera jurídica de las personas naturales y de las jurídicas, desde aquellos Gobiernos que prohíben su uso, como aquellos que aún no regulan abiertamente, y finalmente los tiempos de respuesta y de adaptación de sus legislaciones y reguladores.

Sin embargo, algo en que acuerdan todas las jurisdicciones, es que estas operaciones comportan hechos económicos relevantes y que no podrán escapar de las regulaciones tributarias individuales de cada jurisdicción. Además es esencial para las Administraciones determinar la fuente, la residencia y el respeto de los Tratados para evitar la Doble Imposición, dado la rapidez e internacionalización de las operaciones. Lo anterior representa el nivel de intervención pública del mercado de Criptoactivos, mediante los cuales, en algunos casos se pretende de manera incidental la supervisión, delimitación y control de la actividad, y en otros, su fomento a la integración en la economía formal. Este escenario de intervención pública por medio de la tributación podría traer como consecuencia la construcción de la naturaleza de los Criptoactivos y de las operaciones que se realizan, o usar a la tributación como una forma de limitar las operaciones a través de una excesiva gravabilidad en las operaciones

Por lo tanto, las siguientes consideraciones tendrán como norte dar primero una definición de criptoactivos, seguido de mostrar cómo operan las distintas administraciones tributarias, además de esto, se vinculará el aspecto legal con el aspecto contable, vital para llegar a una armonización entre los aspectos jurídicos y contables que conforman la obligación tributaria. Se tomarán en cuenta diferentes jurisdicciones y cómo estas han abordado la conceptualización y la tributación.

\section{Intervención de la administración en la economía, énfasis en el mercado de criptoactivos}

Dado que esta investigación está destinada no solo para abogados, sino para contadores, ingenieros y cualquier persona con intereses en criptoactivos y la tecnología Blockchain, me detendré a explicar los límites que tiene la Administración 
para intervenir en la economía, y las actividades desplegables. Citando a Daniel Betancourt:

Los Estados, a través de sus normas de Derecho, han sido dotados en mayor o menor medida para intervenir en la economía. Esta intervención tiene como fundamento la corrección de fallos de mercado, en la observancia de valores superiores consagrados en sus ordenamientos jurídicos o en la orientación propia de un determinado modelo económico. Los límites de la intervención se encuentran normalmente regulados normas, principios y valores superiores pivotando, en los sistemas democráticos y en las economías de mercado, en el respeto de los derechos de los particulares y de las situaciones Jurídicas subjetivas (Betancourt Ramírez, 2018, 109).

\section{Límites de la administración para intervenir}

\section{Derechos Fundamentales}

Los derechos fundamentales y las libertades públicas constituyen la esencia misma del régimen constitucional, de allí que sólo pueden ser limitados por normas provenientes del Poder Legislador, es lo que se conoce como reservas de Ley y se deriva de la teoría de la división de poderes (Hutchinson, T., 2016, 109).

Así pues, tanto los derechos fundamentales como las libertades públicas son auténticos límites al poder político, estos imponen un ámbito de libre determinación individual completamente exento del poder del Estado, corolario lógico del Estado liberal de Derecho en el cual el sistema jurídico y político se orienta hacia el respeto y la promoción de la persona humana en su estricta dimensión individual. Los derechos fundamentales y las libertades no son sólo meras barreras a la acción de los poderes públicos, sino un conjunto de valores o fines directivos de la acción de los poderes públicos (Hutchinson, T., 2016, 109).

\section{Libertad Económica}

La Libertad Económica se formula como el derecho de todos a dedicarse libremente a la actividad lucrativa económica de su preferencia. Esta libertad corresponde a todos los sujetos de derecho; sin embargo, no es absoluta, se la somete a las limitaciones previstas en la Constitución y las Leyes por razones de seguridad, sanidad y otras de interés social. 


\section{Principio de Legalidad}

El principio de legalidad consagra la denominada tesis de la vinculación positiva a la legalidad que deben respetar todos los actos de la Administración Pública. No existen para los entes y órganos del Poder Público "zonas deslegalizadas" en las cuales puedan actuar sin la previa habilitación singular o general; por el contrario, tales actos deben ser conformes a derecho, en concordancia con el supuesto de la norma previa.

Debe excluirse toda posibilidad de aceptar la validez de actos de la Administración que no tengan como base de sustentación una norma que le atribuya la competencia para dictarlos, previa y expresamente. Dicho de otra manera: la Ley consagra una interdicción absoluta a todo órgano administrativo que una norma no lo haya autorizado para actuar; por tanto, esa interdicción opera desde el punto de vista subjetivo (ningún órgano) y consecuencialmente también desde el punto de vista objetivo (ningún acto) (Peña Solis, 2001, 700-701) (Lares Martínez, 2001)

\section{Garantía de la Reserva Legal}

La garantía de reserva legal impone que toda actividad o ejercicio de limitación sobre los derechos ciudadanos o libertades públicas debe tener su fundamento en una norma de rango legal, garantizando este principio que no pueden imponerse limitaciones por actos de rango sub-legal o de carácter reglamentario, es decir por normas dictadas por la administración en atribuciones propias del poder legislativo.

Uno de los medios de los cuales se sirve el Estado para intervenir en la economía son los tributos. Visto desde la perspectiva tributaria, el fin de los tributos no se reduce a la recaudación de medios para soportar las finanzas públicas (fines fiscales) sino que pueden tener funciones de ordenamiento (fines extrafiscales) con el objetivo de satisfacer otros cometidos estatales. Precisamente en este ámbito, los tributos, en varias ocasiones, han sido orientados a la regulación (visto el carácter coactivo que tiene el tributo en sí mismo) y al fomento.

Como hemos señalado en los acápites anteriores, coinciden las distintas jurisdicciones en detectar y gravar las transacciones con criptoactivos. En este escenario, sin perjuicio de la necesidad urgente de gravar una fuente de ingresos, que con el paso del tiempo se ha hecho más relevante, para el soporte de las finanzas públicas nacionales, es innegable la pretensión de controlar, delimitar y supervisar el 
mercado de criptoactivos, cuyo origen y confirmación es netamente privado, a través de los tributos. No se trata simplemente de la detracción de rentas o la obtención de ingresos, sino que las distintas administraciones tributarias tienen como objetivo (y reto) el conocimiento de las operaciones, sus partes y las cuantías como forma de intervención pública en la economía.

Por otra parte, el modelo de tributación que sea adoptado y su inserción formal en las economías, puede además servir de fomento al mercado de los criptoactivos en las distintas jurisdicciones, sin denostar la clásica técnica de los beneficios fiscales bajo los preceptos de esta técnica de intervención.

Así las cosas, a pesar de la carencia de instrumentos normativos especiales por las autoridades estatales, la subsunción de las operaciones y transacciones en y de criptoactivos - como medio de cambio por bienes y servicios, como depósito de valor o como unidad de cuenta- dentro de los supuestos de hecho de las normas secundarias tributarias ha sido de las primeras técnicas utilizadas para asegurar la intervención pública en el mercado de los criptoactivos. Por consiguiente, el modelo de tributación que se implemente por las distintas jurisdicciones fiscales encierra el interés de los Estados de controlar o fomentar el señalado mercado.

Para las Haciendas, el logro de los objetivos estatales requiere ineludiblemente de la percepción de ingresos los cuales suponen, a su vez, ciertas erogaciones que en su mayor parte son realizadas por los ciudadanos a favor del Estado. Esta percepción se justifica con la potestad impositiva o el poder tributario, el cual es la manifestación del poder estatal aplicado al punto de vista impositivo.

En definitiva, toda la lógica de la posición tradicional se construyó sobre la base de que el poder tributario emana de un poder superior otorgado per se al Estado (soberanía o supremacía), que constituye el fundamento de la tributación y la forma como se explican las relaciones entre este y los particulares; por tratarse de un poder ilimitado, debe ponérsele freno mediante el establecimiento de garantías otorgadas a los contribuyentes. Con el advenimiento de los Estados modernos, constitucionales y democráticos, buena parte de la doctrina moderna comenzó a rechazar los postulados de esta teoría, oponiéndose a sus dos supuestos fundamentales (Tapia, 2015, 329).

Los criptoactivos al no estar respaldado por ninguna autoridad monetaria central, son monedas voluntarias, en donde ninguno de los intervinientes puede obligar 
a otro aceptar estos medios como forma de pago, además los reguladores deben tomar en consideración el valor de estos activos, ya que en la mayoría de los casos el valor está representado en la confianza y los riesgos asociados a la pérdida del valor son mayores que los títulos emitidos por un Gobierno. Esto da como consecuencia un impacto directo en el pago de bienes y servicios, en las políticas monetarias y la estabilidad financiera de los mercados. El desarrollo de la política fiscal y monetaría, y en consecuencia exigencia del tributo, no es más que la manifestación del poder del Estado sobre los ciudadanos, al igual que la Actividad Administrativa de Policía, estas pueden repercutir negativamente en el establecimiento, desarrollo y desenvolvimiento del mercado de criptoactivos.

No solo se podría limitar el desarrollo de una nueva tendencia comercial, que abarcaría inmensidad de procesos financieros no tradicionales, sino que también, pueden afectar las garantías de los contribuyentes, Legalidad, Igualdad, Propiedad y No Confiscación, Capacidad Contributiva, Proporcionalidad y Progresividad del Sistema Tributario. A pesar de que no todas las jurisdicciones cuentan con instrumentos normativos especialmente legislados para el tema en discusión, varias jurisdicciones han tomado las operaciones y sometido a diferentes análisis, bien sea el Criptoactivo como medio de cambio por bienes y servicios, como depósito, resguardo y garantía de valor, o como unidad de cuenta, estas han sido los primeros pasos para asegurar la intervención administrativa en el mercado. Por tanto, la conceptualización que se tome, además del modelo tributario a desarrollarse por los Estados, puede permitir o no el libre desenvolvimiento de los Criptoactivos en sus respectivas jurisdicciones y a su vez limitar su participación en el mercado mundial.

\section{Conceptualizando los criptoactivos}

\section{A. Breve Introducción a la Blockchain}

En esencia, la Blockchain es una base de datos digital compartida y sincronizada, la cual es mantenida por un algoritmo basado en consenso y almacenada en varios nodos (computadoras que guardan en sus discos duros locales una versión de la base de datos). La Blockchain basa su confiabilidad en la replicación, por lo cual, existen muchos participando en el mantenimiento de la base de esta base de datos. Cada nodo almacena una copia íntegra de esa base de datos, independientemente de las actualizaciones. En cada uno de los nodos, se almacena y se procesa la información de forma descentralizada. Además, la Blockhain puede ser usada como libro de contabilidad segregado agregando datos, solo eliminándolos en circunstancias extraordinarias. 
Se resalta que en Blockchain existen clases distintas de esta tecnología. En efecto no existe una versión única, así encontraremos diferentes formas de distribución de datos que varían desde su perspectiva técnica, arreglos, gobernanza y complejidad. Los estilos de gobernanza se componen en redes centralizadas, descentralizada y redes distribuidas.

Los arreglos de las redes en la que pueda operar una Blockchain, será la realización que se tenga entre los participantes del sistema, así por ejemplo tenemos las redes centralizadas cliente-usuario, eliminando o limitando la toma de decisiones entre los usuarios de la red, ya que solo un ordenador dicta todas las instrucciones y protocolos para la red. De igual forma, esta centralización se puede dar determinado cuantos individuos pueden tomar decisiones y como se relacionan en su orden de jerarquía, y finalmente desde el punto de vista lógico, para la ejecución de estructuras e interfaz, y si este se mantiene en un solo bloque unitario o puede subdividirse y mantener su autonomía.

Ahora bien, uno de los mayores logros de la tecnología blockchain ha sido operar en forma descentralizada, sin embargo, Vitalik explica que a menudo la descentralización es uno de los términos más usados en cuanto al desarrollo de los criptoactivos, siendo este concepto la razón de ser de la tecnología, sin embargo, pocas plataformas, documentos y desarrollos definen con precisión lo que significa operar en una plataforma descentralizada como señala Buterin Vitalik.

Existen diferentes formas de descentralización, cada una independiente de la otra. Al igual que en la centralización, podemos abordar el entendimiento de la descentralización desde: la descentralización de la arquitectura de equipos involucrados, descentralización política y finalmente descentralización de lógica y estructura.

- Descentralización de Equipos: se refiere a la cantidad de equipos participantes en el sistema, para la resolución de los problemas matemáticos y en la obtención de la recompensa, repartida entre los participantes;

- Descentralización Política: esta se refiere a la cantidad de personas que puedan participar en la Blockchain y de estas quienes pueden tomar decisiones dentro de esta, finalmente; 
- Descentralización Lógica y de Estructura: como se mantiene la estructura del sistema y como se realizan las operaciones lógicas, también se puede hablar de cómo opera la red y si esta puede ser divida o segmentada en varios bloques sin alterar su función o contenido.

Continuando sobre este punto Vitalik (Ídem) concluye que la blockchain es descentralizada en cuanto a la distribución de equipos y a los participantes, no obstante, la red opera de forma centralizada o da la apariencia de centralización ya que se mantiene unidad dentro de la cadena y el sistema se comporta como una sola computadora.

\section{B. Conceptualizando los Criptoactivos}

Uno de los mayores retos que presenta el mercado actual, es el acordar una definición unitaria de Criptoactivos, se han acuñado diferentes términos que los legisladores y autoridades regulatorias usan sin discriminación, tales como moneda digital, criptomoneda, criptodivisas, moneda virtual ${ }^{(2)}$ siendo el de moneda digital el uso normalizado.

Comenzaré esta sección abordando una definición basada en las características tecnológicas de los criptoactivos, en su forma más pura puede ser definido como operaciones persona a persona realizadas en forma digital sin la necesidad de acudir a una autoridad central, usando códigos matemáticos en el desarrollo de claves criptográficas para aprobar y confirmar las transacciones realizadas por los usuarios. Así también bajo los esquemas de criptografía se puede garantizar un anonimato parcial.

Esto se extiende a las pruebas de trabajo o proof of work, entre los participantes de la Blockchain, tomaremos como ejemplo Bitcoin, en donde el o los participantes ${ }^{(3)}$ que logren descifrar los códigos para generar nuevos bloques, serán recompensados con fracciones de las nuevas monedas, quedando registrada las transacciones que no pueden ser cambiadas o modificadas. Esta prueba de trabajo se forma bajo el consenso distribuido, es decir todos los procesos que participan en la minería deben ser validados y comprobados a través de una deserción del sistema, Bitcoin añade requerimientos a su cadena, como cálculos matemáticos complejos que requieren ser resueltos por varios equipos computacionales, para llegar a un consenso de aceptación y generar la así la recompensa, o buscar otro bloque más favorable para los participantes. 
Toda su estructura tecnológica conlleva a una solución para uno de los mayores problemas del dinero electrónico, el doble gasto, ya que los archivos donde se encuentran resguardadas las fichas del dinero digital pueden ser copiados o falsificados, realizando diferentes operaciones con la misma cantidad. Sin embargo, las operaciones realizadas en la Blockchain de Bitcoin, estarán protegidas de esto, ya que los repositorios se modifican previa solución de órdenes o problemas matemáticos, sin la posibilidad de poder falsear o modificar la cadena de transacción.

Entonces con esta primera definición podemos señalar las características esenciales de los Criptoactivos descentralizados y de mercado abierto:

— El sistema no necesita una autoridad central. Así, su estado es mantenido a través de un consenso distribuido.

— El sistema mantiene todas las unidades y su propietario.

- El sistema define si se pueden crear nuevas unidades. En este caso, el sistema debe definir las circunstancias de su origen y cómo determinar el propietario de las nuevas unidades.

— Solo se puede asegurar la propiedad de una unidad a un usuario de manera criptográfica.

- El sistema permite las transacciones de unidades, en las cuales se cambia el propietario de dichas unidades. Una transacción solo puede efectuarse si se puede probar ser el actual propietario de estas unidades.

— Si se efectúan dos transacciones sobre las mismas unidades, el sistema solo ejecuta una de ellas.

Desde un punto de vista regulatorio, autoridades como el Departamento de Tesoro de los Estados Unidos, lo define como "un medio de intercambio que funciona como moneda en algunos entornos, pero no tiene todos los atributos de la moneda real”. No solo su definición es la más compleja, sino también las funciones o el propósito de uso.

El Grupo de Acción Financiera Internacional (GAFI) (Grupo de Acción Financiera Internacional, 2015) define los instrumentos tratados como "monedas virtua- 
les distribuidas, de fuentes abiertas, basada en matemáticas persona a persona que no cuenta con una autoridad de administración y ningún monitoreo o supervisión fiscal”. Estas monedas, según esta definición, están basadas en la matemática que está protegida por criptografía, y las cuales dependen de claves públicas y privadas para transferir el valor de una persona a otro y debe ser firmada criptográficamente cada vez que se transfiere. El enfoque del GAFI, se centra en los riesgos de Legitimación de Capitales y Financiamiento al Terrorismo, y la posición que deben tomar los Estados para comprender las operaciones que se realicen con las “monedas virtuales".

El Instituto Americano de Contadores Públicos Certificados (AICPA por sus siglas en inglés) (Association of International Certified Professionals Accountants, 2018) las define de esta manera: la moneda virtual es una propiedad que existe en forma electrónica y se utiliza como una reserva de valor, así como para adquirir bienes y servicios, así como otras monedas virtuales. Los usuarios de moneda virtual pueden cambiarla por dinero físico, como el dólar de los Estados Unidos (USD) u otras monedas extranjeras. Los usuarios también pueden obtener una nueva moneda virtual a través de la "minería”, que es el proceso de hacer que las computadoras compitan para resolver problemas matemáticos complejos. Los individuos con las computadoras que resuelven los problemas son los "ganadores" que reciben bloques de moneda virtual recién extraídos.

La Organización para la Cooperación y el Desarrollo Económicos (OCDE) a través del Proyecto OCDE/G20 publicado en el 2014 (Organización para la Cooperación y el Desarrollo Económicos, 2014) da una primera definición de "moneda virtual”, como "toda unidad digital de intercambio que no esté respaldada por la moneda de curso legal emitida por algún gobierno” las cuales pueden, en sectores específicos de la economía "cambiarse por monedas físicas reales o utilizarse para adquirir bienes y servicios tangibles, mediante intercambios que puedan llevar a cabo terceras partes” (Organización para la Cooperación y el Desarrollo Económicos, 2018).

Ahora, tomemos en cuenta las funciones del dinero, estas funciones son servir como: I) medio de intercambio o de pago, II) unidad de cuenta, y III) depósito de valor. Estas características definitorias del dinero no se adaptaban totalmente a las características intrínsecas en los Criptoactivos descentralizados. Por ejemplo, tomemos la volatilidad en el valor de los Criptoactivos, estas variaciones hacían difícil que estos sean tomados como unidad de cuenta contable, sin embargo, debido a su aceptación ya son utilizados para asignar valor a diferentes bienes y servicios. A esto se le suma la relevancia como medio de intercambio o pago. En países con crisis 
económicas, como Venezuela, es usado como medio de depósito de valor, además de ser usado para adquirir bienes y servicios.

El concepto manejado por las Organizaciones mencionadas anteriormente, responden a un solo criterio, a la descentralización vinculada con los Criptoactivos "tradicionalmente conocidos", sin embargo, ya existen desarrollos e implementación de Criptoactivos Centralizados, principalmente por Gobiernos de China, Suecia, Israel, India y Uruguay, los cuales adquirirán relevancia interna y adquirirán su par al dinero de legal circulación de su territorio (The Law Library of Congress, Global Legal Research Center, 2018).

Para la creación de estos Criptoactivos Centralizados, los Gobiernos deben prestar especial atención a sus sistemas constitucionales, Banco Centrales, reglamentos y reglas de endeudamiento.

\section{La contabilidad para ayudar en el desarrollo del mercado dentro de las empresas}

Como se ha mencionado en líneas anteriores, el uso de los criptoactivos ha crecido exponencialmente en los últimos años, no solo las personas naturales los han incorporado como mecanismo para adquirir bienes y servicios, mecanismo de inversión, y en algunos casos un medio para preservar el valor. Tanta es su relevancia en el mercado actual que la Bolsa de Valores de Nueva York indexo a Bakkt $t^{(4)}$, una plataforma donde se negociarán contratos de futuro y operaciones en el mercado Over The Counter u OTC ${ }^{(5)}$, por sus siglas en inglés.

En la medida que una mayor cantidad de empresas que coticen en bolsa utilicen los criptoactivos, el Consejo de Normas de Contabilidad Financier (Financial Accounting Standard Board, FASB) y la Junta de Normas Internacionales de Contabilidad (International Accounting Standard Board, IASB) tendrán que pronunciarse al respecto para evitar problemas contables concernientes a la comparación de estados financieros. Por lo tanto, establecer el reconocimiento y la medición contable oportunos es importante para efectos de comparabilidad de estados financieros. 


\section{A. Racionalidad y aplicación de la contabilidad para delimitar la actuación administrativa. El derecho y la contabilidad}

Todo texto normativo intenta producir efectos de predeterminación de comportamientos futuros, de restricción de posibilidades de acción. Cuando ese efecto predeterminante es menos preciso, se instaura un espacio de codeterminación del texto (Romero-Muci, 2012, 51).

Se trata de aquellos textos que contienen reenvíos a estándares o a cláusulas generales, que son desde el punto de vista de su estructura lógico-semántica particularmente abiertos y se califican como factores que inciden sobre el grado de discrecionalidad atribuido al intérprete. La renuncia a la predeterminación puede ser voluntaria y corresponder a una técnica legislativa en la que el autor de la norma transfiere la normatividad a otro sujeto u otro contexto. Tomemos como referencia a Hart: el derecho ya no puede ser visto ni descrito desde un punto de vista externo, inflexible, como un mecanismo de coerción, ni de aquel cuya validez depende de su conformidad con las normas de superior jerarquía, en este caso normas de reconocimiento (Hart, 2011, 69) o sencillamente la predilección de cómo actúan los funcionarios, bien sean administrativos o judiciales, en aquel en el que el destinatario es un simple espectador inerte y pasivo (Viola y Zaccaria, 1999, 259).

En el caso de la codeterminación jurídica del derecho por la contabilidad, los reenvíos de los textos jurídicos pueden referirse a conceptos contables, de modo que se hace preciso al intérprete jurídico recurrir a los postulados de la técnica contable y por lo tanto invadir la materia de lo extrajurídico (Romero-Muci, 2012, 52-53)..

En el caso del derecho tributario, cuyas normas y sus supuestos de hechos se nutren de los hechos económicos que el legislador determine como relevantes, tiene como característica el reenvío a conceptos, técnicas, estándares y datos contables, con los cuales se busca develar la realidad económica del contribuyente. Para que el imperativo técnico contable tenga validez, debe ser jurídificado, esto es, reconocido o concretado por las reglas de producción del derecho, es decir, que sea validado por la racionalidad jurídico-formal (García Vizcanio, 1997).

El reenvío a conceptos y técnicas contables produce la necesidad del operador jurídico de trasladarse al lenguaje de la contabilidad, a los fines de interpretar la norma jurídica de acuerdo con el sentido de concepto técnico contable. En la intertextualidad que produce la codeterminación del derecho por la contabilidad, se hace 
difícil al operador jurídico reconstruir el significado de los términos del lenguaje de la contabilidad, ya que estos tecnicismos están caracterizados por una lógica propia que no necesariamente es coherente con el resto del orden jurídico y particularmente con sus valores superiores.

Ello supone la necesaria coordinación de los contenidos jurídicos y contables, de modo que la finalidad jurídica de dirigir conductas hacia objetivos predeterminados sea coherente con la técnica contable y a su vez con los valores superiores en que se enmarca el fin normativo, es decir, que la interpretación resultante tenga como sustrato la racionalidad axiológica. La técnica contable permite maximizar la (1) racionalidad práctica; (2) la racionalidad teleológica y con ella la racionalidad axiológica. No obstante, en muchos casos de codeterminación por el reenvío a conceptos contables, se presentan dilemas, que representan la necesidad de hacer juicios de ponderación, entre la racionalidad práctica versus la racionalidad ética en el sistema jurídico.

La contabilidad es considerada como un sistema de información y una disciplina descriptiva y analítica. A través del cumplimiento de un conjunto de reglas de acción, que conforman la disciplina contable, es posible la sistematización de la información. Este conjunto de reglas de acción es denominado "método contable" cuya expresión más representativa es la anotación por “partida doble”.

La dualidad económica implica que los hechos económicos llevados a cabo por una entidad deben ser expresados por medio de sistemas de contabilidad que den a conocer los dos aspectos que envuelven toda operación. Estos dos aspectos, son (1) los recursos económicos de los cuales dispone para la realización de sus fines y (2) Las fuentes de dichos recursos. El registro del hecho contable lleva intrínseco un determinado orden, fundamentado en el principio de dualidad económica, mediante el cual será posible que la contabilidad cumpla su finalidad como sistema de información, por tanto, las Normas Internacionales de Contabilidad, NIC, juegan un papel de vital importancia para la incorporación de los criptoactivos, al igual que las Normas Internacionales de Información Fiscal (NIIF), ayudan a ir perfeccionando el contenido de las NIC. 


\section{B. Abordar los criptoactivos desde la contabilidad}

Existen innumerables fenómenos en la empresa que se suceden unos de otros, estos hechos pueden producir alteraciones, aumentos o disminuciones en el mercado, o en su patrimonio. Pueden ser realizados a través de hechos económicos, es decir por su propia actividad o valoraciones y variaciones del mercado, estas alteraciones también pueden ser producidas a través de actos dictados por la administración, por lo tanto, es vital para la empresa estar siempre en sintonía con el cumplimiento normativo. La forma más importante que tiene una empresa de reflejar las actividades o hechos económicos son sus estados financieros, en donde se refleja el balance de situación, ganancias y pérdidas, movimiento y flujo de caja, así como las operaciones realizadas en el año fiscal, todos estos documentos se caracterizan por ser fiables y útiles, teniendo que reflejar las operaciones realizadas por la empresa.

Todo esto ayudará a la empresa a evaluar a las actividades que quiere realizar con los criptoactivos, delimitar su hecho económico, evaluar si lo considera como un activo, pasivo o patrimonio, y aplicar las NIC-NIIF correspondientes. Ahora bien, los contadores han clasificado dentro de sus normas el uso de criptoactivos:

- Como Activo: La clasificación como activo es una de las primeras opciones que toman los contadores que actualmente investigan la aplicabilidad de los criptoactivos, esta clasificación los caracteriza como aquellos bienes, derechos y recursos de los cuales dispondrá la empresa, se incluyen aquellos activos que se espera obtener algún beneficio económico en el futuro. Los criptoactivos adquieren bajo esta definición que son propiedad de la empresa y el potencial de adquirir un beneficio económico a futuro.

- Como Inventario: La clasificación de inventario es muy específica para las criptomonedas, y solo se puede realizar bajo una sola circunstancia y siempre basándose a la NIC 2 - Inventarios (International Accounting Standards Board, 2005). Al respecto de esta definición, aunque algunas entidades asimilan las criptomonedas como inventarios, al considerarlas como tal se requiere de 1) un costeo, 2) una identificación individual y 3) que la actividad de la empresa que pretenda tal reconocimiento sea comercial. Si luego de evaluar estas consideraciones la entidad concluye que debe reconocer esta partida como inventario, las criptomonedas se deben medir a valor razonable con cambios en resultados. 
- Como Intangible ${ }^{(6)}$ : una de las posiciones tomadas comúnmente por contadores, economistas y abogados, es clasificar a los criptoactivos como intangibles (se utiliza la NIIF 38, para su reconocimiento como intangible) (International Accounting Standards Board, 2007). La norma señala que se deben cumplir con los siguientes criterios: 1) es probable que los beneficios económicos futuros del intangible fluyan a la entidad y 2) que el costo del activo sea medible. El primer criterio ya fue demostrado en párrafos anteriores, en la medida que se comprará siempre un bien esperando obtener un beneficio económico en el futuro y es probable que se obtenga dicho beneficio puesto que el precio de los criptoactivos como el Bitcoin aún es volátil, lo que permite obtener ganancias por la compraventa del bien. El segundo criterio es que el costo del activo debe ser medido con fiabilidad y la obtención de este costo corresponde al precio pagado inicialmente por la criptoactivos debido a que esta siempre se transa a valores de mercado.

- Como Instrumento de Inversión: Para manejar los instrumentos de inversión dentro de la empresa se requiere la aplicación de la NIIF 9, para que los criptoactivos puedan ser incluidos o considerados deben estar sujeto a una contraprestación o contrato, bien los define el párrafo 2.3 y el 2.4 de la mencionada norma de contabilidad (International Accounting Standards Board, 2012). Esta Norma se aplicará a aquellos contratos de compra o venta de partidas no financieras que se liquiden por el importe neto, en efectivo o en otro instrumento financiero, o mediante el intercambio de instrumentos financieros, como si dichos contratos fuesen instrumentos financieros, con la excepción de los contratos que se celebraron y se mantienen con el objetivo de recibir o entregar una partida no financiera, de acuerdo con las compras, ventas o necesidades de utilización esperadas por la entidad.

Dicho lo anterior, para poder incluir a los criptoactivos dentro de esta NIIF debe contarse con una contraprestación, aquellos criptoactivos descentralizados no califican ya que nadie está obligado por contraprestaciones a transar sobre estas, sin embargo, aquellos criptoactivos que estén sujetos a contratos de futuros, por ejemplo, aquellos transados en Bakkt, pueden calificar dentro de esta NIIF, sea este como principal o subyacente a la obligación. Lo importante aquí este que existe un instrumento contractual que permita registrar las operaciones y sus variaciones durante la ejecución del contrato. 
Una vez definido este punto, uno de los factores claves para el reconocimiento de los criptoactivos se encuentra en su intangibilidad, en un mercado activo y en la propagación en su uso. La intangibilidad, por su parte, formará siempre parte de la esencia de los criptoactivos, puesto que se manejan por una wallet digital(7) en la que cualquier transacción se podrá hacer mediante esta aplicación; el uso en el mercado de los criptoactivos aún está en desarrollo, pero existe un potencial ilimitado en su aplicabilidad al mundo financiero. Por parte del mercado activo, los criptoactivos parecen aún estar adaptándose al sistema financiero global, iniciativas que para bien o para mal se ha logrado con él Petro, propicia un uso más extenso a futuro.

Sin lugar a duda, la cooperación entre las ramas de la Contabilidad y del Derecho representa un pilar fundamental para incorporar con seguridad y sin asperezas los criptoactivos. Ambas ramas podrán de forma efectiva guiar la intervención pública en el mercado, esta necesidad de intervención debe estar acompañada de una comprensión técnica de normas y de tecnología por parte de las jurisdicciones, para llegar a una solución homogénea y dar garantías a los participantes del mercado.

\section{Modelos de tributación de los criptoactivos}

Dicho lo anterior, los criptoactivos han demostrado su abrumador impacto en el mercado, a través de la descentralización, al no estar atado al sistema financiero tradicional, cruzan instantáneamente cualquier soberanía, ¿cómo pueden hacer frente las diferentes jurisdicciones para imponer su potestad tributaria? A partir de la naturaleza de los criptoactivos, se puede colegir, que independientemente del medio tecnológico del que se sirven y que denota su esencia, los mismos puede comportar algunas propiedades del dinero (medio de cambio, unidad de cuenta; y/o depósito de valor) y de activo (“commodities" e instrumentos financieros). La selección de una u otra propiedad ha determinado su definición desde la perspectiva tributaria.

Tomaremos como referencia aquellas jurisdicciones que le entregan a los criptoactivos la clasificación de activos, aquellas jurisdicciones que difieren de este concepto, y aquellas que no permiten, en la actualidad realizar operaciones a través de este medio.

\section{A. Como un activo}

Empezaremos con los Estados Unidos de Norteamérica, el Internal Revenue Services o IRS, califica a los criptoactivos como propiedad, y les otorga las carac- 
terísticas de la permuta a las transacciones realizadas por sus usuarios, también tributan sobre las operaciones de minería, se consideran como fuentes de ingresos ordinarios y se tributan por su valor al momento del año donde fueron minados, los equipos, además reconoce la capitalización y disminución del valor de los equipos utilizados para la minería de criptoactivos. La aplicación del cálculo para su valoración es realizada a través de la ponderación del mercado.

Uno de los problemas que persiste en la actualidad es que diferentes reguladores han clasificado de diferentes maneras a los criptoactivos, no llegando a una conclusión homogénea para que sea aplicada dentro de su jurisdicción. Así, por ejemplo, tenemos a la unidad de inteligencia de Estados Unidos de América, el US Financial Crimes Enforcement Network (FinCen), califica a las monedas virtuales como moneda, a pesar de que no cumplan todos los atributos dentro de la caracterización. Como consecuencia de ello, la señalada entidad establece que los emisores y administradores de las monedas virtuales están sujetos a la normativa de prevención y lucha de blanqueo de capitales y financiación del terrorismo y, por consiguiente, tienen la obligación de registrarse.

Por su parte, el regulador del mercado de futuros, el US Commodity Futures Trading Commision, considera que la criptomoneda Bitcoin tiene naturaleza jurídica de bien (commodity) y a esos efectos, ha emitido diversas alertas.

Canadá, toma posición similar, su fiscalizador define a las criptomonedas como una presentación digital del valor facial del dinero, pero no es moneda legal, es un activo digital, que sirve para la adquisición de bienes o servicios entre los usuarios que han acordado su uso.

A nivel contable, Canadá deja a discreción la valuación por parte de los usuarios, si los clasifica como propiedad o inventario, siempre con la obligación de tomar valores referenciales del mercado al momento de la compra, y al final del año fiscal para ajustarlas ganancias o pérdidas producidas por el mantenimiento de la misma, fecha de las transacciones, comprobantes, valor en dólares canadienses al momento de realizar la operación, dirección de las wallets para comprobación y control de las transacciones, la tasa de intercambio promedio, son las obligaciones que deben cumplir aquellos que operen con los criptoactivos.

Australia considera que los criptoactivos son activos susceptibles de generar ganancias de capital. Así, descartan que sean dinero o una moneda extranjera y entran 
dentro del esquema de operaciones de permuta. Las personas jurídicas que reciben pagos en criptoactivos deben declarar su valor en moneda de curso legal como ingresos ordinarios a los fines de verificar si existió una ganancia. Sin embargo, en lo que respecta a las personas naturales, las transacciones están exentas de tributos bajo las siguientes condiciones: (I) que hayan sido utilizadas como pagos por bienes o servicios para uso personal y; (II) que el valor de la transacción sea inferior a 10.000 dólares australianos. Específicamente, la legislación australiana le otorga características de valor a la criptomoneda, lo cual incide específicamente, desde el punto de vista tributario, en la actividad de minería.

El Reino de España sigue esta línea, reconoce las ganancias o pérdidas de capital producto de los incrementos de valor de los criptoactivos, es necesario integrar en el patrimonio la diferencia entre los precios de compra y de venta de las criptomonedas, como sucede con las acciones de empresas cotizadas y otros productos financieros. Esto repercute tanto en operaciones que implican una criptodivisa y una moneda regulada, como el euro o el dólar, como a las operaciones entre Bitcoin y Ethereum, por ejemplo. La minería y recibir salario también deben tributar bajo esta fórmula, pero, la autoridad fiscal española no ha aportado solución a la depreciación o aumento de valor de los equipos que se usan para minar.

Además, para aquellas operaciones de compra venta de bienes o servicios, deben retener el impuesto al valor agregado, conforme a la sentencia Helvidka C264/14.

México otorga a los criptoactivos la calificación de activo virtual, que está definido por su artículo 30 como "la representación de valor registrada electrónicamente y utilizada entre el público como medio de pago para todo tipo de actos jurídicos y cuya transferencia únicamente puede llevarse a cabo a través de medios electrónicos”. Sin embargo, no existe un esquema de tributación para los criptoactivos en este país.

Argentina, a través de la última actualización del Impuesto a las Ganancias de 2018, incluyo a las monedas digitales, las cuales, por la ambigüedad del concepto utilizados por el legislador argentino, grava las operaciones con Criptoactivos con un 15 \%. El reglamento de la Ley no aclara la ambigüedad conceptual.

No solo se presenta el problema de la falta conceptual, sino que también se presenta el problema de cómo cree el Legislador que debe gravarse el impuesto. Para 
calcular esa base, debemos tomar el precio de venta, restarle el costo de compra (o de minado) y a eso restarle también otras deducciones y gastos. Y aquí nos topamos con el segundo problema: las deducciones y gastos que podremos computar (e incluso la forma de liquidar/calcular el impuesto) variará dependiendo de si la fuente de las ganancias es argentina o extranjera.

Según la Ley, los beneficios derivados de la compraventa de criptomonedas serán considerados de fuente argentina cuando el emisor de esos activos se encuentra en el país. De lo contrario, serán de fuente extranjera. Ahora bien, en el caso de monedas descentralizadas como Bitcoin, por ejemplo, cómo se puede determinar la procedencia o la realización de la operación, la norma no toma un criterio para determinar la fuente para el nacimiento la obligación tributaria.

\section{B. Diferente a un activo}

Las jurisdicciones que no aplican o no consideran a los criptoactivos como un activo, tienen diversas razones, sea para aumentar el atractivo de sus territorios a través de la no gravabilidad de estas operaciones, o bien sea para disminuir la alícuota de tributación. Alemania y Singapur, no los consideran activos financieros, lo califican como moneda privada, así se busca evitar la tributación sobre ganancias de capital, al hacer esto, en Alemania, por ejemplo, mantienen un atractivo para las operaciones de sus Exchanges, como Kraken.

Suiza, en lo que respecta al Impuesto al Patrimonio, determinado individualmente por cada Canton ${ }^{(8)}$, califica los criptoactivos como divisas extranjeras a esos fines. Así, los tenedores de criptoactivos son gravados al finalizar cada año fiscal por el valor de los mismos en su patrimonio. Igualmente, a los efectos de los pagos recibidos por criptoactivos, son computados como ingresos a la conversión al momento de su pago.

Eslovenia no considera las inversiones en estos instrumentos como ganancias de capital susceptibles de ser gravadas por el impuesto sobre la renta. El cómo estas jurisdicciones abordan la fiscalización de los criptoactivos responde a la evolución de las funciones y finanzas estatales, el intervencionismo en el mercado de criptoactivos es una respuesta directa de dirección de los Estados tanto como para la recaudación.

Considerando que el sistema de criptoactivos está en una etapa de formación, se alerta que, si existe poca técnica legislativa en la formación o actualización de las 
leyes tributarias, se incrementaran los impuestos debilitando el mercado, Keynes previene que muchos han entendido que la eliminación de las grandes diferencias de riqueza y de ingresos por medio de la imposición directa-impuestos sobre los ingresos no puede ser llevada muy lejos, por dos reflexiones: 1) el temor de hacer de la evasión hábil un negocio demasiado atractivo, y de disminuir indebidamente el incentivo de correr riesgos; y 2) "por la creencia de que el crecimiento del capital depende del vigor de las razones que impulsan al ahorro individual y que una gran producción de ese crecimiento depende de los ahorros que hagan los ricos de lo que les sobra”.

\section{Jurisdicciones que no permiten los criptoactivos}

La globalización ha permitido el tráfico sin limitaciones de información y bienes, los criptoactivos han auspiciado un crecimiento en la adquisición e intercambio de estos, sin embargo, diferentes jurisdicciones se han puesto en contra de la utilización de este medio tecnológico, las razones para su prohibición es la apariencia de que existen transacciones completamente anónimas ${ }^{(9)}$, las cuales no permiten la identificación o rastreo de las personas.

Aquí entran en juego las monedas privadas o Private Coins ${ }^{(10)}$, utilizan protocolos para garantizar el anonimato y la privacidad de las operaciones, tomare a Monero como ejemplo, Monero logra el anonimato al generar aleatoriamente una dirección única como destino cuando se envía la transacción, rompiendo el vínculo entre la dirección pública de un usuario y una transacción específica, lo que garantiza que su dirección pública no otorgue acceso a su saldo o historial. Además, las transacciones en Monero pasan por mezcladores para agregar una capa adicional de anonimato.

Una clave secreta asegura que el destinatario pueda escanear la Blockchain para identificar las direcciones únicas asociadas a su cuenta y, a su vez, otorgar acceso al historial de transacciones y al saldo solo a terceros confiables. Es en la actualidad una de las monedas privadas con más respaldo y apoyo dentro de la comunidad.

Esto, se suma el temor de que la totalidad de los criptoactivos sirven para legitimar capitales y financiar células y actividades terroristas, ya que este anonimato y no trazabilidad permite escapar del control de las autoridades reguladoras a nivel internacional. 
Finalmente, están prohibidas por sus Bancos Centrales ya que son consideradas activos de altos riesgos sin respaldo en una moneda de curso legal, incluso, Bangladesh ha fijado una pena de 12 años para aquellas personas que realicen operaciones con criptoactivos.

Ecuador, Costa Rica, Honduras, Nicaragua, Islandia, Vietnam y Tailandia, prohíben estrictamente a sus ciudadanos realizar operaciones con criptoactivos. El Banco Popular de China, por el contrario, no lo prohíbe estrictamente, pero veta a sus instituciones financieras nacionales o extranjeras, así como a sus empleados públicos realizar operaciones con criptactivos.

\section{Malta}

La República de Malta es una de las primeras jurisdicciones en destacarse por contar con un sistema regulatorio para los criptoactivos y la tecnología blockchain, este marco normativo se divide en tres normas fundamentales. Estas normativas han profundizado en los detalles intentando abordar algunos de los aspectos más controversiales de estas tecnologías disruptivas. Esto reafirma la determinación de Malta en convertirse en el centro de elección para quienes buscan establecer un negocio relacionado con Blockchain o criptoactivos. El Legislador de Malta, en conjunto con la Autoridad de Servicios Financieros de dicho país (MFSA, por sus siglas en inglés), son elogiados frecuentemente por su capacidad de crear un marco legal dentro del cual las empresas puedan prosperar, ya que no se reprime la innovación, y al mismo tiempo permite a estas operar dentro un ambiente completamente regulado que está en conformidad con la legislación de la Unión Europea.

Las tres normativas se dividen en:

— Ley de Autoridad sobre la Innovación Digital;

— Ley de Acuerdos y Servicios en Tecnología Innovadora;

— Ley sobre Activos Financieros Virtuales;

En conjunto se conocen como el Marco de Innovación Digital, esto permite a cualquier emprendedor o inversor actuar bajo un marco regulatorio claro, que permite el surgimiento del mercado, mejora la confiabilidad, y da certeza legal para su consumo y adopción para la adquisición de bienes y servicios. 
Para el momento de la redacción de este artículo no existe normativa específica emitida por el parlamento maltes, que regule la tributación de los criptoactivos en esa jurisdicción, para el impuesto que grava la renta, sin embargo y en adopción de la Sentencia del Tribunal de Justicia (Sala Quinta) del 22 de octubre 2015, en relación con "Sistema común del impuesto sobre el valor añadido (IVA) —Directiva 2006/112/CE”. Las operaciones de compra venta realizadas con criptoactivos están sujetas a retención del mencionado impuesto.

\section{E. La intervención de Venezuela en el mercado de criptoactivos}

El Gobierno de Venezuela, interviene activamente en la esfera de acción de los particulares, sea con leyes ablatorias de derechos y garantías, sea con expropiaciones en empresas particulares, con nacionalizaciones a sectores económicos de interés para sus fines, en fin, la intervención del Gobierno venezolano en la economía ha sido intensa, no dejando por fuera el mercado de Criptoactivos.

\section{Petro}

El Petro nace por la necesidad que tiene el Gobierno de Venezuela de nuevas fuentes de financiamiento que puedan escapar de las sanciones dictadas por el Ejecutivo estadounidense y de manera menos severa las dictadas por la Comunidad Europea. Este fue inspirado por el fallecido expresidente Hugo Chávez, para crear una alternativa al Dólar estadounidense, esta idea buscaba ser viable para países en desarrollo para que usen sus recursos naturales como respaldo.

Este criptoactivo es importante como objeto de análisis, ya que sus implicaciones no se van a limitar solamente a Venezuela, sino a cualquier país cuyas reservas e infraestructura económica está basada en minerales y petróleo, dándole la capacidad de utilizar sus recursos como garantía para financiar su deuda a través de la creación y anclaje de un commoditie a un criptoactivo.

A través del Decreto Presidencial 3.196, del 8 de diciembre de 2017, se autoriza la primera intervención oficial del Gobierno venezolano, creando la Superintendencia de Criptoactivos y Actividades Conexas (SUPCAVEN) y además la creación y manejo de un Criptoactivo centralizado, el Petro, en sí, el mencionado Decreto busca regularizar la creación y el manejo de las Casas de Intercambio o Exchanges, sin fijar en su funcionamiento el cumplimiento de las normas de Prevención y Legitimación de Capitales, dejando como punto destacado la autoregulación utilizando 
las normas dictadas por las Superintendencia de Bancos y otras Instituciones Financieras o por la Superintendencia del Mercado de Valores para llenar los vacíos creados por el Decreto.

Posteriormente, en fecha 31 de enero de 2018, fue publicada la primera versión beta del Libro blanco (White paper) del Petro, en el cual se establecían especificaciones técnicas de dicho "criptoactivo", las cuales fueron variadas en cuanto su tecnología y contenido en fecha 15 de marzo de 2018 y más recientemente, en fecha primero de octubre de 2018, se conoció una nueva versión. En este orden de ideas, y a través del Decreto 3.292 ${ }^{(11)}$ se determina como respaldo para la implementación de operaciones de intercambio financiero y comercial a través de criptoactivos, el desarrollo potencial de 5.342 mil millones de barriles de Petróleo Original en Sitio (POES), tanto pesado como extrapesado. Esto permitiría a las entidades responsables realizar legalmente actividades de comercialización de criptoactivos que utilicen el petróleo de la reserva nacional especificada como colateral.

Luego, y a través de la Asamblea Nacional Constituyente, se crea una nueva Superintendencia, esta vez, la Superintendencia Nacional de Criptoactivos (SUNACRIP), la finalidad sigue siendo la misma, regular el mercado de criptoactivos, casas de intercambios y todo lo relacionado con el Petro.

\section{¿Cómo se puede clasificar el Petro?}

Como mencione en líneas anteriores, hay que entender los dos tiempos que ha tenido la regulación en materia de Criptoactivos en Venezuela, la primera no menciona una descripción ni para los Criptoactivos, ni para el Petro, solo dicta de forma muy básica las obligaciones de las Casas de Intercambio para operar y comercializar el Petro. Ahora, una vez sale publicado el Decreto de la Asamblea Nacional Constituyente, la legislación define al Petro como un Criptoactivo Soberano “Activo digital emitido y respaldado por la República Bolivariana de Venezuela, bajo la denominación específica que a tal efecto se le confiera”.

Si bien el Petro fue creado con tecnología Blockhain, debemos analizar los elementos que conforman a este criptoactivo. Primero, es emitido por una autoridad central, en este caso el Gobierno de Venezuela, el cual usa como respaldo los siguientes comodities petróleo, oro y diamante, bajo una fórmula referencial que no es aplicada por la Tesorería Nacional de criptoactivos, ya que es el Ejecutivo Nacional quien ha dictado el aumento del precio de forma arbitraria. 
Entender el anclaje de estos comodities al Petro es fundamental, ya que no es una tarea sencilla debido a las incongruencias en las declaraciones dada por el Ejecutivo Nacional y lo descrito en el withepaper. El presidente de la República creo la ilusión de que el Petro podrá ser cambiado por un barril de petróleo, y además le asigno el apoyo de las operaciones de financiamiento en el desarrollo de $5.342 \mathrm{mi}-$ llones de barriles de petróleo en sitio alojados en la Franja del Orinoco. Esto parece implicar que cada Petro generado está atado a un barril físico de petróleo por lo cual cualquier tenedor de este criptoactivo puede cambiarlo. Sin embargo, el artículo 5 del Decreto Presidencial 3.196 se aleja de esta afirmación, indicado que cada tenedor de Petro puede cambiarlo por su equivalente en cualquier otro criptoactivo o por Bolívares de acuerdo con la tasa de intercambio fijada por la Superintendencia, también puede ser cambiada por divisas. En este orden de ideas el artículo 8 que "la colocación inicial se hará a través de subasta o asignación directa, realizada por la Superintendencia de los Criptoactivos y Actividades Conexas Venezolana, de conformidad con el número de barriles en reservas otorgados como respaldo por el Ejecutivo Nacional para el Petro, así como el número de petros que se encuentren en circulación”, si bien este artículo enlaza la primera emisión de petros a un determinado número de barriles, el artículo 5 del mencionado Decreto no permite su cambio por barriles.

A esto, se le suma el Decreto Presidencial emitido por Nicolás Maduro el 23 de febrero de 2018, en donde se designan ciertas zonas de la Franja del Orinoco como apoyo al Petro, así como cualquier otro criptoactivo que pueda ser desarrollado en el futuro, este petróleo, se basa en las reservas mas no en petróleo extraído, por lo cual su valor solo podría en sentido técnico estar anclado a la potencialidad del yacimiento, dando como resultado un menor valor en su valoración, en definitiva, el Gobierno venezolano está dando en garantía por los Petros sus reservas de petróleo pesado y extrapesado.

Esto deja en una situación desventajosa a los poseedores de Petros, ya que su valor estará limitado y será menor a lo establecido por el Gobierno de Venezuela; para poder cambiar por ese barril, se deberá empezar la explotación del yacimiento y dichas reservas deben ser extraídas, lo cual deja dos posibilidades, o los inversores del Petro comienzan a invertir en la exploración y explotación de la Faja del Orinoco, o esperan que terceros interesados lo hagan para así poder obtener el valor mencionado. 
Según lo descrito en el Decreto 3.292, se viola el artículo 12 de la Constitución de la República Bolivariana de Venezuela, el cual dicta: Artículo 12. Los yacimientos mineros y de hidrocarburos, cualquiera que sea su naturaleza, existentes en el territorio nacional, bajo el lecho del mar territorial, en la zona económica exclusiva y en la plataforma continental, pertenecen a la República, son bienes del dominio público $y$, por tanto, inalienables e imprescriptibles (...), con esto, se estaría creando un medio en donde el Estado venezolano da en garantía la rentabilidad del Petro. Tenemos, entonces, que el Petro se asimila a un título valor emitido por la República para financiar el gasto público, y que no puede ser considerado una moneda, a pesar de que pueda emplearse como medio de pago.

Dicho esto, es conveniente recordar qué se entiende en Venezuela por operaciones de crédito público.

De acuerdo con el artículo 80 de la Ley Orgánica de la Administración Financiera del Sector Público, las operaciones de crédito público son aquellas por las cuales el Estado obtiene "recursos que impliquen financiamiento reembolsable" (numeral 6). Entre otras, el artículo alude a la emisión y colocación de títulos valores (numeral 1) y el otorgamiento de garantías (numeral 4).

Si contrastamos la manera en la cual el Petro será emitido para su circulación con el listado del artículo 80, podremos encontrar varias similitudes.

En efecto, ya señalamos que el Petro puede equipararse a un título valor que además implica una suerte de "garantía” de la República, lo que, por cierto, viola el artículo constitucional 12, pues los yacimientos no pueden darse en garantía. Asimismo, explicamos que, según el libro blanco, el Petro permite recaudar fondos para sufragar el gasto público. Hay, por ello, un financiamiento.

Además, ese financiamiento es reembolsable, en el sentido que la República se compromete a aceptar el Petro como forma de pago de obligaciones con el sector público, aplicando para ello un descuento. Esto quiere decir que quien invirtió en el Petro obtendrá un "reembolso" a través del pago de la obligación que está extinguiendo y, además, obtendrá un beneficio equivalente al descuento reconocido por la República.

A pesar de que se trasluce la intención de otorgar los efectos de una moneda fiduciaria al Petro, la Constitución venezolana establece en su artículo 318 que la unidad monetaria de Venezuela es el Bolívar. 
Por consiguiente, dentro de las opciones jurídicas disponibles, descartando la capacidad de ser un "criptoactivo soberano" y de ser dinero fiduciario, el Petro se configura en un valor, asemejado como título de deuda ${ }^{(12)}$ emitido por el Estado venezolano bajo una arquitectura institucional sui géneris. En todo caso, a pesar de la prolífica labor propagandística respecto al Petro que han llevado a cabo las autoridades venezolanas, y la emisión de instrumentos normativos que pareció colocar a Venezuela en un lugar preferencial en la comunidad internacional respecto a la aceptación del uso de criptoactivos.

\section{F. ¿Cómo tributa Venezuela los criptoactivos?}

Las normas venezolanas no han fijado una posición clara acerca de la forma en cómo tributaran los criptoactivos, a través del Decreto N. ${ }^{\circ} 35$ en el Marco del Estado de Excepción y Emergencia Económica ${ }^{(13)}$, en el cual se establece el pago de impuestos para aquellas operaciones realizadas con Divisas o "Criptodivisas", este Decreto solo establece un marco enunciativo, dejando un vació operativo para los particulares y total discrecionalidad a las autoridades para dictar las normas que crean convenientes.

Ahora, extendiéndome sobre este punto, y tomando en consideración las conceptualizaciones en ápices anteriores, me extenderé en el contenido con las normas y reglamentos tributarios venezolanos, la Ley de Impuesto sobre la Renta y su Reglamento , bajo la descripción dada, estas operaciones estarían gravadas como Ganancias de Capital, descrita en el título II de la Ley impositiva venezolana, esto incluirá cualquier criptoactivo, sus “tokens”, y transacciones, el Petro también estaría tributando bajo esta fórmula.

Para los efectos buscados, tomo en consideración las legislaciones que conceptualizan los criptoactivos como una forma digital de activo, sean para adquirir otros criptoactivos o bienes y servicios, a los efectos de la legislación venezolana debemos tomar entonces los artículos $23^{(14)}$ y $38^{(15)}$ del Reglamento, para la acreditación del Impuesto en Venezuela.

La conceptualización por parte de la SUNACRIP a los criptoactivos y al Petro, se encauza como activo, por tanto, el tratamiento fiscal que debe darse dentro de Venezuela debe ser el de renta cedular del $1 \%$, el cual se encuentra en el artículo 74 de la Ley de Impuesto Sobre la Renta, ahora en cuanto al Petro, debido a que su emisor es el Estado, estaría exento de tributación por lo establecido en el artículo 
14 de la Ley. Ahora respecto a la actividad de los mineros y Exchange, además de estar gravada por el impuesto sobre la renta por su actividad empresarial, estos activos deben estar sujetos a la depreciación o revaloración para la obtención de los activos digitales mencionados.

Respecto al Impuesto al Valor Agregado, la transmisión entre usuarios no debería estar gravada por este impuesto, por cuanto la cesión de intangibles no son consideradas operaciones de venta, esto de acuerdo al Decreto Ley que Establece el Impuesto al Valor Agregado, estas definiciones se encuentran en los artículos 1 y 4 , pero, la adquisición de bienes o servicios si deben estar gravadas con el IVA(16).

\section{Conclusiones}

Los Criptoactivos son una de las innovaciones con mayor atención en la actualidad. Dado el crecimiento del mercado de Criptoactivos, se hace necesario para aquellas administraciones interventoras dar definiciones concretas y unitarias, que permitan la subsunción de las prácticas realizadas por los particulares a sus legislaciones correspondientes. Aquellas administraciones que aún tengan dudas en la aplicabilidad y certeza de los Criptoactivos deberían actuar de la mano con los expertos nacionales y establecer zonas de ensayos y regular en función de las actividades realizadas, sin entorpecer o prohibir el desarrollo del mercado.

Esta necesidad de caracterización y definición no puede basarse en una solo característica, sino crear un concepto flexible que involucre diferentes aspectos tales como monedas, medios y sistemas de pagos, plataformas de smartcontracts, commodities, mercado de valores, solo así se garantizará una base sólida para el desarrollo del mercado de criptoactivos, presentes o futuros.

Tomando la conceptualización de los criptoactivos, su clasificación responderá a las distintas finalidades que puedan tener los Estados, bien sea para regular y gravar las operaciones, o fomentar el mercado a despensa de la tributación, con el propósito de recibir grandes inversiones, sin embargo, estas jurisdicciones pueden ser o serán consideradas como jurisdicciones que erosionan la base impositiva.

Sobre el contexto regulatorio actual, este ha demostrado la dificultad que tienen las administraciones para subsumir los criptoactivos dentro de las regulaciones del sector financiero tradicional o del mercado de valores, al no ser flexibles o no estar acorde a las características de los criptoactivos. 
La reconstrucción en el derecho de los conceptos extrajurídicos, como en este caso la contabilidad, implica que los legisladores aborden el universo lingüístico de la disciplina técnica. Una vez reconstruido el concepto no sólo debe responder al fin con que fue insertado en el sistema, sino que se correspondan con los valores superiores del ordenamiento jurídico, así garantizando una mayor precisión técnica en la elaboración de un marco regulatorio actualizado que no requiera mayores modificaciones.

A nivel tributario, una mayor apreciación del fenómeno podrá ayudar a las jurisdicciones en la redacción de nuevas normas fiscales específicas para el mercado de los criptoactivos, a través de guías, normas, reglamentos actualizados, se asistirán a las administraciones y a los individuos en el cumplimiento tributario, minimizando los riesgos de evasión fiscal. En vez de utilizar normas fragmentadas, un código unificado ayudará tanto a la Administración como a los contribuyentes. A esto se le suma que bajo los esquemas de los tratados para evitar la doble tributación se hace necesario revaluar y estudiar mejor por los legisladores, haciendo uso de las técnicas legislativas, racionalidad y objetividad, lo relativo al uso de los criptoactivos y entender su estructura económica, alcance y significancia de la misma para no crear situaciones ilegales.

Las experiencias regulatorias e impositivas de Malta y Venezuela presentan una dualidad de realidades, dando una visión diametralmente opuesta en cuanto a los esquemas regulatorios y claridad normativa para acceder al mercado de criptoactivos, estas responden a los intereses que puedan tener sus líderes, sin embargo, sus esquemas regulatorios pueden ser objeto de estudio para las administraciones que pretenden regular, y como en el caso de Venezuela, acuñar su propio criptoactivo.

Aquellas jurisdicciones que quieran crear sus propios criptoactivos, cómo se vio en el caso de Venezuela con el Petro, deben prestar especial atención a sus reglas de endeudamiento, políticas monetarias y reglas fiscales, y la forma en cómo realizan su acuñación digital. Pueden tomar especial consideración en la convertibilidad con su par en su moneda fiduciaria, esto ayudaría en la aceptación como medio de pago, y anclándose al Impuesto al Valor Agregado por el pago de bienes y servicios, cambiando la concepción en su tenencia, como se expresó en líneas anteriores, en el caso de EE.UU. son considerados como activos, así en teoría el IRS podría considerar la compra de cualquier bien como una venta/ganancia de capital y sujeto al impuesto sobre la renta, diferente es el caso alemán que para el caso de operaciones compra venta, las asume como moneda de curso legal. 


\section{Referencias}

Association of International Certified Professionals Accountants, AICPA. (2018). Virtual Currency Guidance. Recuperado de https:/www.aicpa.org/content/ dam/aicpa/advocacy/tax/downloadabledocuments/20180530-aicpa-commentletter-on-notice-2014-21-virtual-currency.pdf

Lares Martínez, E. (2001). Manual de Derecho Administrativo. Caracas: Exlibris.

Hart, H. (2011). El Concepto del Derecho. Buenos Aires: Abeledo Perrot.

Betancourt Ramírez, D. (2018). La Tributación Como Forma de Intervención Pública en el Mercado de Criptoactivos. En Jornadas de Derecho Tributario de la Asociación Venezolana de Derecho Tributario, Caracas, Venezuela.

García Vizcanio, C. (1997). Derecho Tributario, Consideraciones Económicas y Políticas. Buenos Aires: De Palma

Peña Solis, J. (2001). Manual de Derecho Administrativo (Vol. Primero). Caracas: Estudios Jurídicos. Tribunal Supremo de Justicia.

Romero-Muci, H. (2012). El Derecho (y El Revés) de la Contabilidad. Serie Estudios, 94. Caracas: Academia de Ciencias Políticas y Sociales.

Tapscot, D. y Tapscot, A. (2018). La Revolución Blockchain, Buenos Aires: Valleta.

Tapia, J. (2017). Revista de Derecho Tributario, (32), 13.

Viola F. y Zaccaria G. (1999). Derecho e interpretación: elementos de teoría hermenéutica del Derecho. Madrid: Dykinson

The Law Library of Congress, Global Legal Research Center (2018). Regulation of Cryptocurrency in Selected Jurisdictions: Argentina, Australia, Belarus, Brazil, Canada, China, France, Iran, Israel, Japan, Jersey, México, Switzerland. Recuperado de https://www.loc.gov/law/help/cryptocurrency/ regulation-of-cryptocurrency.pdf 
Grupo de Acción Financiera Internacional, GAFI (2015). Directrices para un Enfoque en Riesgo: Monedas Virtuales: Convertible. Recuperado de http:// www.fatfgafi.org/media/fatf/documents/Directrices-para-enfoque-basada-en-riesgoMonedas-virtuales.pdf

Organización para la Cooperación y el Desarrollo Económicos, OCDE. (2014). Proyecto OCDE/G20 de Erosión de la Base Imponible y Traslados de Beneficios. Acción 1: Objetivo del 2014. Recuperado de https://www.oecd .org/ctp/Action-1-Digital-Economy-ESP-Preliminary-version.pdf

Organización para la Cooperación y el Desarrollo Económicos, OCDE. (2018). Resumen de los Desafíos Fiscales derivados de la Digitalización: Informe Provisional 2018. Recuperado de https://www.oecd.org/tax/beps/resumendesafios-fiscales-derivados-de-la-digitalizacion-informe-provisional-2018.pdf

International Accounting Standards Board (2005). Normas Internacionales de Contabilidad NIC N. ${ }^{\circ}$ 2. Recuperado de http://www.normasinternacionalesde contabilidad.es/nic/pdf/NIC02.pdf

International Accounting Standards Board (2007). Normas Internacionales de Información Fiscal, NIIF N. ${ }^{\circ} 38$. Recuperado de https://normasinternacionales decontabilidad.es/nic/pdf/niif3.pdf

International Accounting Standards Board (2012). Normas Internacionales de Información Fiscal, NIIF N.o 9, Instrumento Financieros, Definiciones. Recuperado de https://www.mef.gob.pe/contenidos/conta_publ/con_nor_co/ vigentes/niif/NIIF9_2014_v12112014.pdf

\section{Jurisprudencia}

Unión Europea (2015). Tribunal de Justicia Europeo (Sala Quinta). Sentencia del 22 de octubre de 2015. Recuperado de http://curia.europa.eu/juris/document/ document.jsf?docid=170305\&doclang=ES

\section{Bibliografía}

De Secondant, C. (Montesquieu) (1988). El espíritu de las leyes. Santiago de Chile: Ercilla. 
Alemania

Germany Won't Tax You for Buying Coffee With Bitcoin. Recuperado de https://www .coindesk.com/germany-considers-crypto-legal-equivalent-to-fiat-for-taxpurposes

Argentina

Ley para Regular las Instituciones de Tecnología Financiera, Diario Oficial de la Nación del 9 de marzo de 2018. Recuperado de http://www.diputados.gob.mx/ LeyesBiblio/pdf/LRITF_090318.pdf

Canadá

Canadian Revenue Agency, Digital Currency Taxation. Recuperado de https://www. canada.ca/en/revenue-agency/programs/about-canada-revenue-agency-cra/ compliance/digital-currency/cryptocurrency-guide.html

Malta

Ley 43, Gaceta del Gobierno de Malta N. ${ }^{\circ} 19.994$ del 22 de mayo de 2018. Recuperado de https://parlament.mt/media/94207/bill-43-innovative-technology-arrangements -and-services-bill.pdf

Ley 44, Ley de Innovación Digital, Gaceta del Gobierno de Malta N. ${ }^{\circ} 19.994$ del 22 de mayo de 2018. Recuperado de https://parlament.mt/media/94210/bill-45malta-digital-innovation-authority-bill.pdf

Ley 45 de Activos Financieros Virtuales, Gaceta del Gobierno de Malta N. ${ }^{\circ} 19.994$ del 22 de mayo de 2018. Recuperado de https://parlament.mt/media/94209/bill44-virtual-financial-assets-bill.pdf

Singapur

Estado de las criptomonedas: no una moneda de curso legal, no regulado. Recuperado de https://thenoticiasbitcoin.com/como-los-paises-han-estadoclasificando-las-criptomonedas-en-todo-el-mundo/ 
Venezuela

Brewer-Carias, A. (1990). Reflexiones sobre la Constitución Económica. Recuperado de http://www.allanbrewercarias.com/Content/449725d9-f1cb-474b-8ab241efb849fea8/Content/II.4.301.pdf

Constitución de la República Bolivariana de Venezuela, Enmienda Número 1, Gaceta Oficial Extraordinaria 5.908, del 9 de febrero de 2009. Recuperado de https://www.oas.org/juridico/mla/sp/ven/sp_ven-int-const.html

Decreto Constituyente sobre el Sistema Nacional de Criptoactivos, Gaceta Oficial 41.575 del 30 de enero de 2019. Recuperado de https://www.petro.gob.ve/ files/gaceta-oficial-41.575.pdf

Decreto $N^{\circ} 2.163$, mediante el cual se dicta el Decreto con Rango, Valor y Fuerza de Ley de Reforma Parcial del Decreto con Rango Valor y Fuerza de Ley de Impuesto Sobre la Renta, publicado en la Gaceta Oficial N. ${ }^{\circ} 6.210$ Extraordinario del 30 de diciembre de 2015. Recuperado de http://www.bod.com.ve/media/97487/GACETA-OFICIALEXTRAORDINARIA-6210.pdf

Decreto con Rango Valor y Fuerza de la Ley Orgánica de la Administración Financiera del Sector Público, publicado en la Gaceta Oficial Extraordinaria N. 6210 del 25 de diciembre de 2015. Recuperado de http://www. traviesoevans.com/memos/2015-12-30-6210-extraordinario-5.pdf

Reglamento de la Ley de Impuesto Sobre la Renta, publicado en la Gaceta Oficial $N^{\circ}$ 5.662 Extraordinario del 24 de septiembre de 2003. Recuperado de http://www.defiendete.org/html/de-interes/LEYES\%20DE\%20VENEZUELA/ LEYES\%20DE\%20VENEZUELA\%20III/REGLAMENTO\%20DE\%20LA\% 20LEY\%20DE\%20IMPUESTO\%20SOBRE\%20LA\%20RENTA.htm

Decreto N. ${ }^{\circ}$ Gaceta Oficial Extraordinaria N. ${ }^{\circ}$ 6.396, del 21 de agosto de 2018, Decreto Reforma que Establece la Ley del Impuesto al Valor Agregado. Recuperado de http://www.cpzulia.org/ARCHIVOS/Gaceta_Oficial_21_08_ 18_num_6396.pdf 
México

Ley para Regular las Instituciones de Tecnología Financiera, Diario Oficial de la Nación del 9 de marzo de 2018. Recuperado de http://www.diputados.gob.mx/ LeyesBiblio/pdf/LRITF_090318.pdf.

\section{Notas}

${ }^{1}$ A los efectos del presente artículo, se utilizará el termino de "Criptoactivos", ya que el mismo concepto agrupa todo el universo actual de monedas digitales, iniciativas de creación o sus fases iniciales de capitalización, y los "tokens "resultantes.

${ }^{2}$ La definición de Moneda Virtual es utilizada por el Grupo de Acción Financiera (GAFI), en su publicación del Directrices Para un Enfoque en Riesgo: Monedas Virtuales, 2015, Recuperado de https://www.fatf-gafi.org/media/fatf/documents/Directrices-para-enfoque-basada-en-riesgo-Monedas-virtuales.pdf, sin embargo la denominación "virtual" es incorrecta, dado que una moneda virtual solo sirve para funciones específicas, limitadas a comunidades en la red que las acepten, funcionaria solo en ciertos entornos o ambientes, carente de toda usabilidad ante el mercado global. Virtual y digital no son sinónimos y usar indiscriminadamente los términos puede llevar a consecuencias no deseadas en el desarrollo del mercado. Por ejemplo, Nikki Levy en su libro The Handbook of Digital Currency, señala que virtual se asemeja a algo cercano a la realidad y no es un concepto neutral.

${ }^{3}$ La cantidad de bitcoins creada está programada y no puede alterarse por mucho esfuerzo y energía que se emplee en la prueba de trabajo. Esto se consigue mediante un proceso llamado ajuste de dificultad, lo que puede que sea el aspecto más ingenioso del diseño de Bitcoin. Conforme un mayor número de personas deciden tener bitcoins, el valor de mercado de la moneda aumenta, y esto hace que la minería de nuevas monedas sea más rentable, lo que lleva a más mineros a gastar más recursos en solucionar problemas de pruebas de trabajo. Que haya más mineros significa más energía de procesamiento, lo que se traduciría en llegar a las soluciones de la prueba de trabajo más rápido, aumentando así la tasa de emisión de nuevos bitcoins. Pero, a medida que aumenta la capacidad de procesamiento, Bitcoin incrementará la dificultad de los problemas matemáticos necesarios para desbloquear las recompensas de minería y garantizar así que los bloques sigan tardando cerca de diez minutos en producirse.

${ }^{4}$ https://www.theice.com/products/72035483/Bakkt-Bitcoin-USD-Daily-Futures-Contact 
${ }^{5}$ Uno de los problemas con la asunción de los criptoactivos como intangibles es la forma en cómo se ha interpretado, al subsumirlo como activo intangible lo asumen como una representación digital de valor, eliminando un factor de control externo, como lo son las llaves de acceso o de los dispositivos de almacenamiento físicos que pueden contener los criptoactivos, eliminando una de las características otorgadas por las NIFF. A esto debe sumarse que la norma contable los identifica como: Plusvalía generada internamente, Subvenciones del Gobierno, Privilegios de Competencia, Marcas, Patentes y Desarrollos, y con un periodo de vida que puede estar definido a nivel legal, así como limitaciones en su alcance de apreciación. Por lo tanto, considerar a los criptoactivos como un intangible debe ser superada.

${ }^{6}$ Wallet Digital o Billeteras Digitales son dispositivos electrónicos o servicios en líneas que permiten a los usuarios realizar transacciones electrónicas. Permiten el almacenamiento de dinero y en algunos casos permiten la vinculación de cuentas bancarias. Así también existen dispositivos físicos que permiten el almacenamiento de las claves criptográficas, accesos o los criptoactivos adquiridos.

${ }^{7}$ La autoridad Suiza, divide los Cantones en: a) Impuesto a la Riqueza, el cual se determina para el 31 de diciembre; b)Impuesto sobre la Renta para la percepción de salario en criptoactivos; c) Operaciones de trading profesional, y; d) Impuesto a las Ganancias de Capital, http://www.loc.gov/law/help/cryptocurrency/switzerland.php

${ }^{8}$ El anonimato en las operaciones con criptoactivos no son enteramente anónimas, estas pueden ser tranzadas bajo esquemas de apodos o nicknames, sin embargo, antes de poder tranzar deben cumplir con requisitos de información mínimos establecidos bien sea por casas de intercambio o Exchange, o también aquellos datos que pidan los actores del mercado OTC.

${ }^{9}$ Las monedas privadas ocupan un nicho dentro de la industria de los criptoactivos que muchos en adoptar las criptomonedas consideran esenciales. Después de todo, el propio Bitcoin a menudo se conoce incorrectamente como una forma anónima de transferir valor, pero la cadena de bloques de Bitcoin es inherentemente pública y una vez que una dirección de billetera se puede vincular a un usuario, todo el historial de transacciones se hace público. Las monedas de privacidad resuelven este problema mediante el empleo de una serie de técnicas diferentes, que brindan a sus usuarios un medio verdaderamente anónimo y de privacidad para intercambiar valor. https:// www.getmonero.org 
${ }^{10}$ Decreto $N^{\circ}$ 3.292, mediante el cual se determina como respaldo para la implementación de operaciones de intercambio financiero y comercial a través de criptoactivos, el desarrollo potencial de 5.342 MMBN de Petróleo Original en Sitio (POES) pesado y extrapesado, de acuerdo a una certificadora internacional independiente, localizado en el Bloque Ayacucho 01, de la Faja Petrolífera del Orinoco Hugo Chávez Frías, publicado en la Gaceta Oficial N. ${ }^{\circ} 41.347$ del 23 de febrero de 2018.

${ }^{11}$ Se menciona al lector la Orden Ejecutiva 13827 de 19 de marzo de 2018, prohibió a personas de ese país y dentro de ese país —en la amplia cobertura legal de esos términos- la adquisición, transacciones y uso del Petro, por ser considerado un instrumento de financiamiento del gobierno de la República Bolivariana de Venezuela.

${ }^{12}$ Decreto 35, del 28 de diciembre de 2018, mediante el cual se dicta en el Marco del Estado de Excepción y Emergencia Económica, Mediante el cual los Sujetos Pasivos que Realicen Operaciones en el Territorio Nacional en Moneda Extranjera o Criptodivisas, Autorizadas por la Ley, deben Determinar y Pagar las Obligaciones en Moneda Extranjera o Criptodivisas, Gaceta Oficial Extraordinaria N. ${ }^{\circ} 6.420$ del 28 de diciembre del 2018.

${ }^{13}$ Estado de Excepción o Emergencia Económica es un instrumento inconstitucional, que ha permitido al Ejecutivo Nacional dictar Decretos diversas materias, su objeto y sucesivas prórrogas coliden con lo establecido en el Artículo 338 de la Constitución de la República Bolivariana de Venezuela.

${ }^{14}$ Dicta el Reglamento que el ingreso bruto global de los contribuyentes estará constituido por el monto de las ventas de bienes y prestaciones de servicios en general, de los arrendamientos de bienes y de cualesquiera otros proventos, regulares o accidentales, tales como los producidos por el trabajo bajo relación de dependencia o por el libre ejercicio de profesiones no mercantiles y los provenientes de regalías o participaciones análogas, salvo disposición en contrario establecida en la Ley.

${ }^{15}$ Así el Reglamento en su Artículo 38 dicta que el costo de los bienes adquiridos o producidos por el contribuyente será determinado el siguiente: 1. - El de los bienes muebles será igual al precio neto de adquisición más los gastos de transporte y seguro, los gastos necesarios de agentes y comisionistas, los derechos consulares, los impuestos de importación y demás gastos y contribuciones directamente imputables al costo de los bienes adquiridos. 2. - El de los bienes inmuebles será igual a su precio al incorporarse al patrimonio del contribuyente conforme al respectivo documento, más el 
monto de las mejoras efectuadas, así como los derechos de registro pagados por el contribuyente. Se excluyen los intereses y demás gastos financieros y de cualquier otra índole.

${ }^{16}$ Esto fue lo que hizo la Asamblea Nacional Constituyente, a través una reforma integral a la norma del Impuesto al Valor Agregado (IVA), con el fin de ampliar las exoneraciones a productos de la cesta básica, establecer una alícuota variable para los consumos gravados que fluctuará entre 8 \% y 16,5 \% según lo determine el Ejecutivo Nacional, aparte de fijar una sobretasa de entre $5 \%$ y $25 \%$ a bienes y servicios pagados con moneda extranjera y/o criptomonedas o criptoactivos distintos al Petro. Recuperado de https://es.scribd.com/document/444790327/0-Reforma-IVA-130120\#from_embed 